\title{
JOSÉ ÁNGEL VALENTE COMO ESCRITOR GALLEGO. NOTAS SOBRE LA INFLUENCIA DE VICENTE RISCO Y ROSALÍA DE CASTRO'
}

\author{
JOSÉ ÁNGEL VALENTE AS A \\ GALICIAN WRITER. NOTES ON THE \\ INFLUENCE OF VICENTE RISCO \\ AND ROSALÍA DE CASTRO
}

\author{
Margarita García Candeira \\ Universidad de Huelva
}

Resumen: Este artículo ahonda en la vinculación de José Ángel Valente con la literatura y la cultura gallegas. Se examinan ciertas intertextualidades significativas presentes en el poemario Cántigas de alén y en otros textos, que revelan la huella insoslayable de Vicente Risco a la hora de establecer una lógica del asentamiento que viene a contradecir la poética explícita del autor (fundada, como se sabe, sobre una potente conciencia exílica) y que acaba proyectándose sobre la lectura que Valente hace de Rosalía de Castro. Materiales como la biografia, las cartas, el Diario anónimo o el catálogo de la biblioteca del poeta permiten contextualizar estas deudas en un entramado de sociabilidad afectiva e intelectual que ayuda a comprender la incardinación específica del poeta en el espacio cultural gallego, caracterizado por el conflicto y la diáspora.

Palabras Clave: José Ángel Valente; literatura y cultura gallegas; Cántigas de alén; Vicente Risco; Rosalía de Castro.

Aвstract:This article explores José ÁngelValente's link to Galician literature and culture. Meaningful intertextual presences displayed in the collection Cántigas de alén and in other texts are evaluated. They reveal the inescapable mark of Vicente Risco in establishing a logics of settlement that comes to contradict the explicit

1 Este artículo se enmarca en el proyecto de investigación financiado «Cartografias del afecto y usos públicos de la memoria: un análisis geoespacial de la obra de Rosalía de Castro» (Referencia: FFI2017-82742-P). 
poetics of the author (founded, as known, on a strong conscience of exile) and which ends up projected upon Valente's reading of Rosalía de Castro. Materials as biographies, letters, the Diario anónimo and the catalogue of Valente's personal library allow to contextualize these debts within a framework of intellectual and affective sociability that helps to understand the poet's specific incardination in the Galician cultural space, as characterized by conflict and diaspora.

KeY words: José Ángel Valente; Galician literature and culture; Cántigas de alén; Vicente Risco; Rosalía de Castro.

Existe un cierto consenso crítico alrededor de la obra poética que José ÁngelValente compuso en lengua gallega, las célebres Cántigas de alén que el escritor nacido en Ourense redactó a partir de los años ochenta del pasado $\operatorname{siglo}^{2}$, y que tiene que ver con el carácter un tanto diferencial del tratamiento del lugar de origen que se da en ellas y que las contrapone a las evocaciones infantiles trazadas en otras piezas de su producción poética escrita en español. Si bien Martínez Falero (2010: 80) coloca las Cántigas al margen de las dos etapas (social-esencial) en las que se ha venido dividiendo la trayectoria del poeta, Fernández Rodríguez las liga a un impulso de «recuperación del paraíso perdido de la infancia y el pasado míticos, que lleva aparejada, además, la recuperación de la lengua originaria» (2008: 141). Por su parte, Mera Herbello detecta que «se ó longo da obra en español nos atopamos cunha serie de poemas que mostran a un poeta pouco identificado coa súa terra, na obra en galego vemos totalmente o contrario» (2002: 143), algo que atribuye a una «evolución intelectual» anclada en la experiencia vital del exilio y a cuestiones de antropología de las lenguas empleadas (2002: 145). Pero es quizá Rodríguez Fer quien más se ha demorado en esta distinción, describiendo cómo, en la escritura valentiana en castellano - tanto poética como ensayística一, el recuerdo de su localidad natal, Ourense, va unido a un matiz afectivo caracterizado por la hostilidad y el desprecio hacia lo que se describe como un clima cerrado,

2 Valente escribe el grueso de estas piezas motivado por una conferencia sobre las Cantigas de Alfonso X que pronunció, a petición de Xan Anllo, en Ginebra en 1980; estas serían objeto de una primera edición en 1981. A ellas se irían añadiendo otras compuestas más adelante que serían publicadas conjuntamente con las anteriores en 1989 (Rodríguez Fer, 1989: 16-18). En 2017, Rodríguez Fer realizó una edición de Cántigas en la que se reúnen varias piezas más, y que se presentó como la edición completa de la poesía gallega de Valente. 
provinciano y sordamente opresor, el propio de la posguerra en el interior gallego. En los numerosos y documentados trabajos que ha dedicado a la faceta gallega de Valente, Rodríguez Fer explica que «las connotaciones temáticas del espacio galaico no siempre son las mismas en los textos gallegos que en los castellanos» (1995: 129) y se refiere a composiciones como "De la no consolación de la memoria», «Fuego-Lolita-mi capitán», «Tiempo de guerra» y "Lugar vacío en la celebración" ${ }^{3}$ para detectar en ellas "una visión sórdida y terrible de la ciudad natal» (1995: 133). Rodríguez Fer relaciona esta condición negativa con la remisión referencial de estas piezas a «un periodo histórico concreto» y sitúa en este punto la distancia que las separa radicalmente de su escritura en gallego:

Tal sombría imagen del lugar nativo, asociado a un periodo histórico concreto, no se encuentra en ninguna de las cántigas gallegas, donde el pasado aparece evocado de un modo intrahistórico y, por tanto, con un carácter mítico y antropológico mucho más trascendente. En realidad, en la crítica poética expresada en castellano habla de Ourense como de una oscura periferia provinciana, mientras que en la obra gallega evoca la tierra nativa como metonimia del espacio mítico del origen (1995: 133).

No obstante, las causas y consecuencias de este desajuste no parecen haber sido demasiado exploradas por el cada vez más abultado volumen crítico generado en torno a la obra de Valente, que ha dependido, demasiado a menudo, de las directrices interpretativas formuladas por el propio poeta en sus entrevistas y, sobre todo, en sus ensayos. Tampoco ha sido estudiada la procedencia, intelectual y tropológica, de los recursos que sirven al ejercicio mitificador de Valente, y que cristaliza en ese corpus híbrido y extrañado que son las Cántigas. Efectivamente, estas presentan la peculiaridad de inflexionar la coherencia de la trayectoria autorial realizando una suspensión de su poética explícita, fundada, como se sabe, en el exilio y el descentramiento. Las composiciones explotan el tropo del regreso, con frecuencia a través de múltiples estrategias que denuncian su Lolita-mi capitán» (2006: 731-733) pertenecen al volumen de prosa El fin de la edad de plata (1973), mientras que "Tiempo de guerra» (2006: 193) se incluye en La memoria y los signos (1960-1965) y «Lugar vacío en la celebración» (2006: 283-283) en El inocente (1967-1970). 
imposibilidad, en un despliegue aporético que, no obstante, no logra ocultar una fuerte atracción hacia el origen que revela un carácter casi ancestral y que está tocada por el sesgo esencialista que denuncia toda maniobra mitificadora como inevitablemente mixtificadora.Al lado de las posibles razones biográficas, este apego tiene que ver, a mi parecer, con la sólida impronta en Valente de una determinada tradición literaria y cultural gallega, la de la Xeración Nós y, en especial, la del polígrafo ourensano Vicente Risco, al que le unieron vínculos personales e intelectuales. Estas páginas quieren ser una indagación que profundice en las huellas específicas que la imaginación de Risco deja en los textos deValente, mostrando la incardinación de este poeta en una determinada corriente de pensamiento sobre lo galaico, que acaba filtrando, en parte, su aproximación a figuras señeras de la tradición gallega como Rosalía de Castro. Nos apoyaremos también en documentos como el Diario anónimo, el catálogo de la biblioteca personal de Valente, el epistolario y las dedicatorias, desde la convicción de que estos materiales, un tanto marginales respecto a la obra acabada en la consideración tradicional y canonizada del hecho literario, proporcionan una información valiosísima a la hora de identificar e iluminar zonas de hondísimo interés en la producción de Valente, no exentas de irradiaciones ideológicas singulares.

\section{EL ALÉN Y LA TIERRA. LA HUELLA DE VICENTE RISCO}

Como se apuntaba más arriba, no son escasas las pistas que podrían haber llevado a examinar en profundidad las distintas inflexiones de la impronta que Risco deja en Valente. En la biblioteca del poeta se atesoran numerosas obras del autor de Leria, con varios volúmenes dedicados por este, y distintas ediciones de títulos clave de la producción de este autor, muchas de ellas con marcas de lectura, señales que revelan la sugestión que Valente sentía por la trayectoria de su paisano ${ }^{4}$. Además, el epistolario cruzado tanto con Vicente como,

Valente atesoraba hasta dieciséis volúmenes de Risco. Además de un tomo de los dos en que dividió Akal su obra completa, tiene tres (del primero al tercero) de los siete que Galaxia editó a mediados de los 90. Como volúmenes sueltos, en su biblioteca están títulos señeros como Leria, Mitteleuropa, A emoción da terra, O porco de pé o el Libro de las horas, con una dedicatoria del autor. Una de las señales que muestran el interés de Valente por un determinado autor es el hecho 
sobre todo, con su hijo Antón es de los más nutridos entre todos los mantenidos con autores gallegos, y Rodríguez Fer, en el capítulo que abre el primer volumen de la serie Valente vital (2012: 83-92), detalla con minuciosidad las múltiples conexiones vitales del poeta con el entorno personal y creativo de la familia Risco.

El propioValente se refirió en numerosas ocasiones a la cercanía afectiva y admiración intelectual que le unía al autor de Nós, os inadaptados, e hizo ostentación explícita de esta. Le dedica las Cántigas de alén, identificándolo como «mestre», y cuando, en la presentación en 1992 del libro Edipo abandonado y otras farsas, del también ourensano José Luis López Cid, se ve impelido a hacer memoria de su horizonte intelectual iniciático, no tiene ninguna duda en asegurar: «Primero, Risco, su impalpable magisterio envolvente» (Valente, 2008: 1480). Quizá haya que explicar la ausencia de investigaciones que incidieran en ese espacio de indagación en principio prometedor por la aparente contradicción que presentan las poéticas explícitas de ambos autores, que dificilmente podrían ser más opuestas desde sus aproximaciones respectivas a la naturaleza del acto de creación poética. Si para Valente, como se sabe, este tenía que ver con una condición de exilio radical, que enlazaba con distintas tradiciones de heterodoxia intelectual y con un entendimiento del lenguaje como desposesión, Risco basó su entendimiento de la cultura y la literatura, en especial las gallegas, en el vínculo esencial que une al ser humano y a la colectividad con la tierra, en una exaltación de las raíces que funda la axiología espacial que contrapone aldea a ciudad y que impregna prácticamente toda su trayectoria intelectual. Frente a Valente, que a menudo emplea el caso del pueblo judío, del que llega a identificar trazos históricos en el área gallega, para apoyar su perspectiva creadora desterritorializada, Risco ve incluso en los numerosos éxodos hebreos la falsa excepción que confirma su poética del asentamiento:

Mais o profesor americano Burgess tiña chegado á definición da nación ideal como: «unha poboación dotada d'unidade

de contar con varias ediciones, a veces en distintas lenguas, de una obra específica, lo que ocurre con varios de los títulos de Risco. Así puede verse en García Candeira y Redondo Abal (2016). Un examen detenido de las marcas existentes en los libros informa también de sus prácticas como lector, pues Valente tenía tendencia a enmendar todas las erratas e incorrecciones que encontrara. Eso ocurre con algunos de los títulos mencionados en este trabajo, como se irá explicando. 
étnica qu'habita un terreo dotado d'unidade xeográfica». Contra d'esto poñen o caso dos xudíos que compoñen unha nación ben definida, espallados pol-o mundo inteiro, hastra falando lingoas deferentes, xunguidos soio pol-os vínculos do sangue e da tradición. Mais esquecen o sionismo, esquecen qu'o que mais xungue ós xudíos é cecais a lembranza da terra de Canaan. Hai un nacionalismo israelita, mais este nacionalismo fúndase na espranza de volver á terra; os xudíos non son unha nación: é unha raza que arela a recostitución da sua nacionalidade. A nacionalidade supón a terra (Risco, 1920: 17$)^{5}$.

Este pasaje de Teoría do nacionalismo galego (1920), considerado como uno de los documentos fundacionales de este programa político ${ }^{6}$, probablemente condense a la perfección la distancia fundamental que separa los programas discursivos de los dos escritores. Quizá por ser consciente de sus peculiares connotaciones ideológicas es por lo que Valente, si bien no tiene reparo en encarecer la ascendencia de Risco, sí opta por desviarla hacia el polo de lo estilístico e imaginativo: así lo hace en su artículo «Vicente Risco o el estilo como virtud» (1962), en el que cifra la enseñanza del maestro en una especie de ascetismo verbal que contrapone al virtuosismo de la «literatura inflacionista» propia de las «formas neoclásicas y neobarrocas de la posguerra» (2008: 1119) y que, como joven poeta,

Se ha transcrito la cita literalmente de la primera edición de la obra de Risco, evitando su adaptación a la actual normativa de la lengua gallega escrita.

6 El texto de Risco está reconocido como la contribución teórica fundacional del nacionalismo gallego, como explica Miguélez-Carballeira (2014: 131). Valente comparte esta apreciación sobre Risco, a quien considera, en su texto «Castelao 86» (1986), como «la aportación del nutriente teórico del pensamiento nacionalista gallego» (2008: 1343). En una conferencia de 1980, no transcrita, dedica atención a las propuestas que Risco formuló en un documento parcialmente similar, "O programa do nazonalismo», como expone Rodríguez Fer (2012: 113-114).

7 Valente explica: «Hay en materia de estilo una distancia abismática entre el virtuosismo y la virtud. Tanta que, por lo general, en el virtuoso del estilo suele el estilo carecer de virtud. Las palabras, en la pluma del virtuoso, tienen una propensión obscena a multiplicarse, a brillar, a ascender hinchadas por su propio sonido como globos en el vacío. El virtuosismo es un crecimiento contra natura del medio verbal y una forma evidente de destrucción del estilo. Porque la virtud del estilo consiste precisamente en servir y no ser servido. Por eso el escritor ha de conseguir que su estilo sirva, pues solo de ese modo se liberará de la insidiosa tiranía de las palabras. El estilo será, así, al propio tiempo, una forma superior de servidumbre y libertad» (2008: 1118-1119). En la reseña de La puerta de 
había aprendido a través de los comentarios que Risco publicaba en un periódico local.

Sin embargo, existen ecos de esos valores espaciales en la obra gallega deValente, que se cifran no solo en el tratamiento mitificado del lugar de origen sino, también y de modo más específico, en un impulso de atracción hacia este que imbuye toda la isotopía del retorno y que, además, se plasma en ocasiones en una identificación de la tierra con lo femenino y lo maternal que afecta incluso a su aproximación lírica a la figura de Rosalía de Castro. Podemos comenzar a explorarlo a través del análisis de la propia configuración del concepto de alén alrededor de un pensamiento paradójico que, proponiendo una nostalgia basada en aporías, no logra ocultar su remisión al origen. La crítica ha tendido a explorar esta noción, aludida mediante un vocablo dificilmente traducible al castellano, a partir de sus remisiones a un tiempo o a un espacio mitificados ${ }^{8}$, pero no se ha detenido a exhumar posibles filiaciones escriturales. Sin embargo, "O alén» es el título de un breve artículo queVicente Risco publicó en febrero de 1922 y que fue compilado posteriormente en el volumen Prosas de Risco en La Zarpa (1921-1923), que vio la luz en 1982.Valente lo leyó: en su biblioteca hay una edición que muestra signos de su empleo ${ }^{9}$. A propósito de una pieza teatral homónima

paja (1953) que publicó el mismo año en la revista Índice, Valente explora cierto conflicto moral en la obra y la función de la magia (2008: 879-882). Rodríguez Fer ha cifrado la influencia literaria de Vicente Risco en Valente en la conexión con la vanguardia que este representaba (2012: 84) y explica que fue el autor de Nós, os inadaptados quien dio a conocer la obra de Manuel Antonio al joven poeta $(2012$ : 84, 88).

8 Podemos repasar estas aproximaciones de modo muy sucinto: Rodríguez Fer, que se detiene en explicar la peculiaridad semántica del término (1992: 86), alude a una distancia temporal y espacial (1992: 94) que tiene que ver con la diáspora (1992: 92). Para Fernández Rodríguez, el alén está ligado al regreso a la memoria (2008: 488), algo que secunda Mera Herbello al asumir su conexión con «recordos nunca idos» (2002: 146). Para Mera, el alén se vincula también a Ítaca, en la medida en que ambos formulan una «distancia precisa nunha linguaxe poética abocada á reflexión como única maneira ou vía de achegamento ás respostas non sempre satisfeitas» (2002: 150). También Carmen Blanco, en un texto de vocación lírica, alude al «lugar da permanente e repetida procura sempre anceiada» (2000: 36).

9 La pieza «O alén» está inmediatamente antes del texto «Agrarismo e ruralismo" (Risco, 1982: 57-58). Entre ambos hay una tarjeta en la que Valente anota «Basilio ÁLVAREZ en la Enciclopedia Gallega (para un texto que debo escribir sobre la biblioteca de mi adolescencia)». Alude, evidentemente, al dirigente del movimiento agrarista, cuya biblioteca heredó la familia de Valente cuando 
de Jaime Quintanilla, Risco formula una reflexión que tematiza el carácter contradictorio del alén tratando de invalidar las categorías convencionales de tiempo y espacio. El germen de la distancia está en el origen, y el futuro no es otra cosa que la esperanza del pasado. Así, explica que "cecais a espranza sexa poñérmol-o pasado diante dos ollos, aló no lonxe, para encamiñarmos car'a íl o noso andar; que cecais andamos por cobiza de desandarmos» e invita a «[a]gardar así, é sempre agardal-a volta do que xa foi noso, a eterna espranza saudosa, e cecais no sexa moita tolería agardar qu'esta mesma saudade volva a traguel-os mortos a esta vida» (Risco, 1982: 55). No es dificil comprobar que este pensamiento paradójico está puesto al servicio de la anulación de los contrarios y, de modo solidario, redunda en un entendimiento de la alteridad comprendida en el alén en términos de mismidad, a pesar de esa inquietante referencia a la vuelta de los antepasados muertos.

Por otra parte, en el volumen misceláneo Leria, que sin duda Valente leyó también ${ }^{10}$, puede hallarse una cierta génesis de esta formulación: Risco cita unas palabras de Castelao que conectan el ansia de regreso propio de los gallegos con la localización, ya vista en las palabras arriba citadas, del futuro en el pasado a través de la imagen, profundamente nostálgica, de una esperanza localizada en el ayer. El de Rianxo decía lo siguiente: «E na volta ó lar énchense os nosos desexos. Os galegos non temos a luz da esperanza diante de nós, témola detrás de nós, enriba do pazo ou da chouza onde nascemos» (Castelao, en Risco, 1990: 16). El juego de equivalencias espaciotemporales, que cruza la contraposición entre ayer y mañana con la existente entre ida y vuelta, éxodo y retorno, queda por tanto confirmado. Podría aventurarse que este gusto por la alteración de

Álvarez tuvo que exiliarse, pero el hecho parece dar fe de una lectura atenta de estas prosas periodísticas por parte del poeta gallego que, como se ha dicho más arriba, cifraba la ejemplaridad de su precursor en el estilo desplegado en sus colaboraciones periodísticas.

10 En la biblioteca de Valente se conservan dos ediciones de este libro, una de 1961 y otra de 1970, y ambas presentan marcas de lectura. En la primera, Valente apostilla el breve texto «O filósofo do progreso» con una nota al margen en la que alude a Hegel (Risco, 1961: 188). En la segunda (Risco, 1970), aparecen marcas de lápiz en las páginas 64 y 73. Además, entre ellas se encuentra una ficha manuscrita en la que el poeta ensaya una traducción al castellano de la cantiga de Mendiño «Sediam'eu na ermida de San Simón», que versiona como «Estaba yo en la ermita de SS». Las citas realizadas más arriba se corresponden con otra edición de la obra más reciente, de 1990. 
la cronología es una clave que marca el pensamiento de Risco, y que se extenderá incluso a la explicación que, en Nós, os inadaptados (1933), ofrece de su primera evolución desde un posicionamiento vanguardista reticente a cualquier inflexión nacionalista al galleguismo conservador. En este texto, también recogido en Leria, presenta este giro como motivado por un descubrimiento de que la auténtica modernidad radicaba en la tradición, en este caso en la autóctona gallega (1990: 65-66), mostrando cómo, de nuevo, el futuro se halla en el pasado, que es hacia donde debe mirar el presente.

Desde esta deliberada confusión entre tiempos podemos entender la peculiar dialéctica que se despliega en las Cántigas. No es demasiado distinta la enseñanza que traen las aguas míticas en el poema «Dicer de tódalas augas»: «Da beiramar fuxín, / subín ó monte. / Hoxe dícenme as augas: / —Mañán é onte» (Valente, 2006: 519). La traslación del pasado al futuro está también presente en la composición "Asedio» (2006:517), pues tras un exordio en el que se saluda a las palabras ("verbas») procedentes "como do alén dun soño, / do alén do tempo e do acordar», se las describe como inscritas en una dislocación temporal parecida a las anteriores, al definirlas como «serodias verbas non nacidas aínda». Esta alteración o desordenamiento tiene una de sus variaciones fundamentales en un juego apórico semejante que opera sobre las categorías de partida y retorno, como he estudiado en otra parte (García Candeira, $2013)^{11}$. No obstante, un examen detenido permite comprobar que esa tentativa no logra obliterar del todo la prevalencia del impulso centrípeto, de enraizamiento y retorno, en los textos de las Cántigas. La composición «Homaxe», dedicada a Rafael Dieste, se fundamenta en un saludo al precursor que regresa, probablemente fundiendo su figuración como exiliado que retorna, un tanto épicamente, con la sobrevenida de su influencia poética: «Mais ti voltache / como voltan os héroes e os reis mortos / na non distinta luz do mencer» (Valente, 2006: 521). Esta figuración se repetirá en el acercamiento a Rosalía de Castro efectuada en los poemas «La poesía» (perteneciente a Breve son, de 1968) y «Rosalía».Aprovechando los conocidos versos del cantar popular glosado en la séptima pieza de Cantares gallegos, «fun ó muiño / do meu compadre; / fun polo vento, / vin

11 Se trata de un análisis de las Cántigas de alén como retorno simbólico que plasma la ambivalente condición afectiva del exilio intelectual, a menudo unido a sentimientos de rechazo y culpa. 
polo aire» (Castro, 2013: 160), Valente los recrea como «Se fue en el viento, / volvió en el aire / [...] / Se fue en el viento, / quedó en mi sangre. // Volvió en el aire» (2006: 237) en el primer texto y, ya en gallego, como "Volveu no aire», en un texto de las Cántigas al que volveremos (2006: 527). Todos estos ejemplos van desvelando una particular distribución de la lógica espacial en torno a una contraposición distinta de la que pretenden promulgar, y certifican la condición compulsiva del retorno a la tierra.

Se genera así una tácita poética del asentamiento que, en su peculiar y paradójica conexión con la nostalgia, es deudora no solo del pensamiento deVicente Risco sino, en general, de toda la teoría identitaria formulada por los miembros de la Xeración Nós y que manifiesta también ecos de otras constantes tropológicas, fuertemente ideologizadas, que han mostrado su potencia y recorrido en la conceptualización acerca de lo que quiera que pueda ser la identidad gallega. En el ya mentado texto «Teoría do nacionalismo galego», se asumía la naturaleza metafisica del «sentimento galego», que generaba en el hombre de esta tierra lo que Risco denomina la «emoción do sedentarismo», pero que hace conjugar con una potente inclinación a la melancolía, generando un entendimiento de la famosa «saudade» como «cobiza do lonxe» paradójicamente arraigada en la posesión de lo propio:

[O] sentimento radical da nosa afectividade étnica é a adoración á Terra. —iTerra a nosa! é o noso berro- que se manifesta de cote en toda a nosa espresión artística. É, coma se dixéramos, a emoción do sedentarismo.Y-a adoración á Terra, e mais a saudade, cobiza do lonxe — se non son duas modalidades do mesmo sentimento- danse tan envolveitas, tan entretecidas unha na outra, que non pudemos ainda separalas, na nosa y-alma, nin xiquera por vía d'astraución analíteca (Risco, 1922: 23).

Formulaciones semejantes aparecen en $" \mathrm{O}$ sentimento da terra na raza galega», publicado en 1920 y también recogido en Leria, un texto que rebasa lo descriptivo para convertirse en un auténtico documento programático concebido como «principio dunha ética e mais dunha estética» (1990:19) basadas, evidentemente, en el «sentimento relixioso da terra» (1990: 11) que Risco va explorando e identificando en toda la tradición cultural, no solo literaria, gallega. A pesar del vuelco ideológico del autor, que abrazará el fascismo 
después de la guerra civil, estas ideas serán reiteradas décadas más tarde en "La poesía gallega en el siglo XIX», capítulo con el que contribuye a la Historia general de las literaturas hispánicas que coordina Guillermo Díaz-Plaja, otro hombre de singular singladura, a la altura de 1957. Pero en ellas aparece lo que será otro leitmotiv que también alcanzará fortuna hermenéutica, y es la tendencia a escoger la alegoría nacional como clave interpretativa de los textos. Esto, sin duda, se percibe en el énfasis realizado en todos los cantos al alba que aparecen en la temprana literatura gallega, identificados rápidamente como emblemas del renacimiento de la lengua, la literatura y la nación gallegas a partir del periodo significativamente evocado como «Rexurdimento»: así, Risco (1957:371,357) reproduce versos ilustrativos de Añón y Pondal. Esta línea argumentativa se proyecta sobre la obra rosaliana, cuyos Cantares gallegos encarnarían el glorioso despertar de un sujeto en el que se da la perfecta fusión romántica entre vate y Volkgeist: «identificada con nuestro pueblo, nuestro pueblo canta en sus versos. Galicia había encontrado su poeta, y así fue reconocido por propios y extraños» (1957:373).

No es una idea demasiado distinta la que expresa Valente en el texto «Rosalía de Castro o el deslumbramiento» (1985), en el que, siguiendo a Xesús Alonso Montero, relaciona el carácter auroral de la colección de 1863 con el cultivo de una lengua neonata por parte de Castro: «En Cantares se siente el gozo — es ese un libro tierno y violento, dolorido y gozoso de oír hablar, como recién engendrada de sí, la lengua. Se asiste al fenómeno primordial de la articulación: la lengua se articula y se dice o se profiere poéticamente por vez primera, al cabo de los siglos» (Valente, 2008:1340). Esta reflexión, que sin duda explica en parte la elección, porValente, de una modalidad lingüística no normalizada para sus Cántigas ${ }^{12}$, permite presentar a

12 La modalidad lingüística de las Cántigas ha sido estudiada por Rábade Villar (2009), que destaca su carácter intraducible. Mera Herbello subraya el empleo del dialecto oriental, alejado de la norma ya por entonces establecida (2002: 154). A pesar de poseer documentación sobre las decisiones normativas referentes al gallego en su biblioteca y tener un evidente conocimiento de ellas, el poeta se negó a que su ortografía fuera revisada conforme a ellas. En otro lugar he relacionado esta reticencia a la norma con las apreciaciones de Deleuze y Guattari acerca de la lengua dañada de Kafka, relevantes en la defensa que los primeros hacen de una «literatura menor» (García Candeira, 2013: 118). A este respecto, es relevante que Valente subrayara, en su ejemplar de los 7 ensaios sobre Rosalía (1952), el fragmento en el que Carvalho Calero alaba el sermo vulgaris escogido por Castro para sus Cantares (Pimentel et al., 1952: 26). 
la escritora padronesa como la personificación más acabada de esa particular «alborada» individual y colectiva: «Y el poeta y la lengua amanecen y se cumplen a un tiempo» (2008: 1340) ${ }^{13}$.

Sin duda, todos estos nódulos conceptuales confluyen de modo complejo en los textos de la colección que estudiamos. Podemos tomar la cántiga quinta como ejemplo señero (Valente, 2006: 511). Después de un inicio de fusión erótica, aparecen dos versos que sitúan la enunciación en una conjunción que reúne «ialba» (amanecer) y «voz», en una clara rememoración de las claves interpretativas que acabamos de ver. El contenido de esa voz no parece ser otro que la formulación de esa paradoja que sitúa la posesión en la lejanía y que bebe, sin duda, de la definición de Risco de «a cobiza do lonxe»:

\author{
Cerquei, cercache, \\ cercámolo teu corpo, o meu, o teu, \\ coma si foran só un soio corpo. \\ Cercámolo na noite.
}

Ergueuse á ialba a voz do home que pregaba.

Terra allea e máis nosa, alén, no lonxe.

El resto del poema es igualmente significativo. El sujeto lírico declara haber recibido el mensaje de esa tierra propia pero lejana — «Ouvín a voz»— e inicia un proceso de acercamiento a un punto caracterizado por la aporía, en la medida en que desdeña y esquiva la noción convencional de verticalidad, pues, se nos dice, se baja a lo alto y se sube a lo hondo ("[b]aixei ó outo / de ti, subín ó fondo»).

13 El fragmento completo de Valente dice así: «Despertar de la lengua, los Cantares: "Después de una larga noche de silencio", escribe Alonso Montero. Noche de siglos. En Cantares se siente el gozo - es ese un libro tierno y violento, dolorido y gozoso de oír hablar, como recién engendrada de sí, la lengua. Se asiste al fenómeno primordial de la articulación: la lengua se articula y se dice o se profiere poéticamente por vez primera, al cabo de los siglos. / Y el poeta y la lengua amanecen y se cumplen a un tiempo. Pues en Cantares, con independencia de obvias variables de intensidad o de madurez, de extroversión o de adentramiento, se da ya por entero el poeta total que Rosalía es: poeta de la expresión individual extrema que se constituye a la vez como poeta de la expresión colectiva extrema. Consustancial a la obra de Rosalía en sus tres libros y en sus dos lenguas, ese rasgo la diferenciaría de su coetáneo Bécquer, cuya influencia sin duda recibió, y por él, en cierto modo, lo aventajaría» (2008: 1340). 
Ese punto parece ser también un lugar de anulación de toda división temporal — «no eixo / do día e maila noite»-, pero, sobre todo, de colapso de toda escisión identitaria: «no eixo / [...] / de ti e de min». El concepto clave es el de «inseparación», que, como el de «inretorno», parece negar la unión invalidando la existencia de una división previa. No es difícil comprobar cómo, en cierta medida, la dinámica aquí trazada produce una cierta revocación de la alteridad mediante la eliminación de la diferencia, algo a lo que ayuda la aparición, muy recurrente en el poemario, del verbo "ficar» (permanecer, quedar): «Fiquei, fun ti. // E ti ficache / coma ti es, pra sempre / acesa»:

Ouvín a voz.

Baixei sobor teu corpo.

Abríuse, améndoa.

Baixei ó outo

de ti, subín ó fondo.

Ouvín na raia

do sol, no achegamento

e na inseparación, no eixo

do día e maila noite,

de ti e de min.

Fiquei, fun ti.

E ti ficache

coma ti es, pra sempre

acesa.

Sin duda, este ímpetu fusionador tiene mucho que ver con el potente carácter erótico de la imagen sobre la que se erige la pieza: estamos ante una inmersión en una materia, sobre la que inevitablemente se proyectan los ecos de la «tierra» mencionada inmediatamente antes, que está claramente identificada con una condición femenina. Eso se hace evidente en su caracterización como "cuerpo» $\mathrm{y}$ "améndoa» que se abre, y en el empleo del femenino «acesa» para marcar un rasgo que no está mermado por la precariedad de lo contingente, sino que responde a una naturaleza siempre igual a sí misma: «E ti ficache / coma ti es, pra sempre / acesa». 


\section{ALBA, FECUNDIDAD Y \\ SAUDADE. LA REPRESENTACIÓN \\ DE ROSALÍA DE CASTRO}

En este acto de penetración en una almendra palpitan ecos de la propia teoría poética de Valente, que, como se sabe, en los «Cinco fragmentos para Antoni Tàpies» incluidos en Material memoria (1979), explicaba que «[c]rear lleva el signo de la feminidad. No es acto de penetración en la materia, sino pasión de ser penetrado por ella» (2006: 387). Esta postulación, cuyo lastre esencialista ha visto Jonathan Mayhew $(1991 ; 1997)$, está sin duda relacionada con la poética de la retracción que Valente ensaya en ese mismo programa teórico, y la propia Rosalía de Castro aparece como protagonista de este singular trabajo de excavación cuando el poeta nos dice, en el texto ya visto, que «ninguna otra mujer después de santa Teresa entra como ella entra, con tal plenitud, en la palabra» (Valente, 2008: 1339), y es ciertamente sintomático que sea precisamente «[1]a penetración de Rosalía en la lírica de lengua castellana» la que restaure, para Valente, la presencia o primacía de la lejana lírica medieval gallega (2008: 1340). En este sentido, la dialéctica germinativa que se deriva de esa poética femenina acaba encontrando vías de confluencia con ciertas fuentes muy potentes en el imaginario conformado en torno a la cultura gallega, que muy a menudo adjudica a la tierra un rol maternal. La lógica de la tierra madre aparece formulada en Risco, quien, a propósito del carácter mayoritariamente masculino de los que emigraban, concluye en su texto "Unha muller na paisaxe» (1949) que hay en la tierra "certo carácter sacro de maternidade» que acaba explicando el «enigma do matriarcado» gallego (1990:140, 142), pero esa unión de tierra y maternidad será un lugar común que parece haberse extendido a través de las décadas hasta llegar a permear la obra de autores tan distintos generacionalmente como Otero Pedrayo, Rof Carballo y Manuel Rivas, tal y como explica Miguélez-Carballeira (2014: 46) en su ensayo sobre la compulsión afectiva que preside las propuestas identitarias para Galicia.

Sin duda, también preside toda la isotopía de fecundidad que se plasma en las Cántigas en una serie de términos como "semente», «formento», «seitura» y "pan», que unen productividad y arraigo. En el poema "Asedio», ya citado, se formula una interrogación retórica que resalta la procedencia remota de las palabras, pero también declara su pertenencia a una poderosa lógica del enraizamiento: 
«Seitura, as verbas, / de qué fonda semente, / formento / de qué lonxano pan» (Valente, 2006:517-519). Idénticos motivos aparecen en la composición «Nenia» (2006:523), que apenas puede disimular la impronta vallejiana ${ }^{14}$ a la hora de formular una elegía a la infancia que toma la forma de la imposibilidad de recibir y compartir el pan con una instancia bajo la que palpita, sin duda, la sombra de la efigie materna:
Ouveaban os cas.
A chuvia
caeu do esluido
ceo do teu ollar no máis adentro
de min.
Eu inda como o pan que mollabas
no brancor da mañá e nos teus beizos
pra desnoitar ó neno
que fun, que son, agora que somente
podería partir, con quén, o pan,
o mesmo pan que ti me tiñas dado.

Preguntado por el carácter matriarcal de la cultura gallega en una entrevista realizada por José Méndez,Valente recuerda con afecto la impronta que dejó en él una infancia efectivamente transcurrida entre mujeres (Valente, 2018:378). Este dato es relevante para iluminar la poética de senectute que no dejan de transmitir las Cántigas, en la medida en que la vuelta a la niñez cobra un papel destacado como fuente de evocaciones presididas por esa modulación nostálgica que es la «señardá» (2006: 509, 527). En ella podemos ver cierta sintonía con la nostalgia promulgada por la Xeración Nós como constitutiva, junto con el humorismo y el lirismo, de la personalidad gallega. La formulación, ya vista, de Risco encuentra cultivo entre intelectuales

14 En numerosos poemas, Vallejo rememora la infancia y la figura maternal a través de las comidas compartidas y el reparto del pan. En particular, la deuda del poema de Valente con la composición 23 de Trilce (1922) es obvia, como muestran los últimos versos del deVallejo: «Tal la tierra oirá en tu silenciar, / cómo nos van cobrando todos / el alquiler del mundo donde nos dejas / y el valor de aquel pan inacabable. /Y nos lo cobran, cuando, siendo nosotros / pequeños entonces, como tú verías, / no se lo podíamos haber arrebatado / a nadie; cuando tú nos lo diste, / ¿di, mamá?». Un poco antes se había referido a una «Tahona estuosa de aquellos mis bizcochos / pura yema infantil innumerable, madre» y a la donación materna de «aquellas ricas hostias de tiempo» (Vallejo, 2005: 177-178). 
contemporáneos y es obvio el diálogo que con él entabla el Ensaio histórico sobre a cultura galega (1933), otro influyente texto en el que Ramón Otero Pedrayo recoge la impronta melancólica de la conspicua saudade. Ya Risco reconocía su origen celta y su relación con el saudosismo portugués (1920: 31-32), contribuyendo a crear un vínculo clave para una proyección geográfica específica:la atlántica, que diferenciaría a los habitantes del oeste ibérico de la racionalidad mediterránea. Este programa imagológico está también presente en Castelao, a través de quien llega a Valente, dato especialmente relevante para comprender el alcance de las fértiles connotaciones simbólicas de las Cántigas. Es muy sintomático el texto «Castelao 86», en el que el poeta reivindica la vigencia de las tesis de Castelao sobre la autonomía gallega, incidiendo en la apertura de sus postulados nacionalistas hacia un federalismo ibérico similar al del socialismo internacional (Valente, 2008: 1344). Lo fundamental es que Valente asume el programa atlantista que Castelao relaciona con la condición lírica, brumosa y alógica del ser gallego, y lo asocia con la existencia de un vigoroso impulso utópico, que ensanchaba las raquíticas vías posibilistas a las que se había reducido la acción política formalizada en los años ochenta. Dice Valente:

«Los gallegos — desliza oblicuamente la voz de Castelaono somos hombres lógicos, quizá porque nos anubla los ojos la brisa del Atlántico». La lógica, en efecto, está en la burda reducción de la política al arte de lo posible, en la desmovilización de lo imaginario colectivo, en el pragmatismo del poder que atiende sobre todo a la perduración de este, en el hábil zurcido del discurso electorero que se teje y se desteje a la vez, en el hilo inconsútil de la caciquería y el clientelismo. Todo lo que Castelao combatió.Todo lo que, pertinazmente, sobrevive. No, no somos hombres lógicos. La utopía, por eso (2008: 1344).

Sin duda, este filtro hermenéutico se suma a los elementos ya vistos a la hora de iluminar el acercamiento poético queValente realiza a Rosalía de Castro en la compleja composición de las Cántigas que lleva el diáfano título de «Rosalía» (2006: 527), y que se construye como un homenaje explícito a una precursora de la que, además, se aprovechan y recrean intertextualmente símbolos como la «sombra» y versos como los célebres «Ahí va la loca soñando» (Castro, 2019: 130), procedente de la colección En las orillas del Sar (1884). 
El comienzo del poema de Valente presenta a una Rosalía en un significativo y paradójico regreso, que está presidido por una lógica móvil y dinámica que parece explotar el enérgico impulso centrífugo y desterritorializador presente en gran parte de la producción rosaliana (RábadeVillar, 2011). Estamos ante una Rosalía marítima, que en principio semeja reacia a cualquier tentativa estática o estabilizadora y que une su retorno a una peculiar diseminación de su palabra poética más allá de la tierra:

«Rosalía»

Volveu no aire.

Alongouse nas verbas

ata atinxi-lo mar.

La segunda parte del poema es, no obstante, muy reveladora del entramado imagológico e ideológico que cristaliza en la prefiguración de Castro que construyeValente: en la alusión a esa problematización de la vista, que queda impregnada de niebla («e nós / velamos os teus ollos / nunha gota de chuvia»), reconocemos el insoslayable eco de la melancolía tradicionalmente asociada al ser gallego en la tradición analizada, que tiene una oscilación concreta en la formulación de Castelao recogida por Valente. Las conexiones son innegables, y el supuesto déficit lógico de este pueblo se cierne sobre ese personaje femenino que ya se autocaracterizaba como «loca». Pero hay otro tópico que también deja cierta impronta en estos versos, y es el de la conversión de Castro en una especie de santa laica, en un proceso que arranca del texto «Los precursores», de Murguía, y que tendría numerosas y exitosas reformulaciones a lo largo del siglo xx, como han estudiado Ferrari (2017), Miguélez-Carballeira (2014: 111) y Rábade Villar (2018a) ${ }^{15}$. Se trata de una operación en ocasiones desactivadora que llevó a acuñar el apodo de "santiña» para Castro, y que no es muy distinta de la que afectó a Machado y que llevó a Jorge Guillén a referirse irónicamente a «nuestro san Antonio de Collioure». En cierta medida, la presentación de una Rosalía que sobrevuela — «por enriba de nós»— los mares conducida

15 Marta Ferrari (2017) estudia la instalación de la santidad rosaliana como tropo interpretativo a partir de la retórica elegíaca del poemario $A$ mi madre (1863). Miguélez-Carballeira evalúa la intervención que, en este proceso, tuvo Carré Aldao (2014: 107-119). Rábade Villar conecta a Rosalía con el elenco de "santos culturales» de formaciones culturales europeas no estatales (2018a: 21). 
por «brancas barcas» remeda, por una parte, la dinámica elevadora de la asunción de la virgen María, pero, sobre todo, recuerda al rito de las procesiones marítimas gallegas, que pasean la imagen de la Virgen por la costa en las festividades locales (especialmente en la del 16 de julio). El énfasis en la palabra "sombra» — «sombra, sombra túa e de nós»- efectúa una remisión automática a la relevancia que este símbolo adquiere en la obra rosaliana y es la que, con toda su apertura semántica, permite que el legado de esta autora se defina como continuado y perpetuo: «E vas, e aínda vas / do soño escuro polo eixido, tola / de noite e señardá»:

As brancas barcas lévante no lonxe con fitas loiras por enriba de nós, e nós velamos os teus ollos nunha gota de chuvia que se nos vai abrindo cara o dentro de ti como o teu margurado corazón se abríu.

Ficou. - Ahí va la loca soñando.

E vas, e aínda vas do soño escuro polo eixido, tola de noite e señardá.

Nas sombras, soia, acesa, branca, sombra, sombra túa e de nós.

No obstante, los últimos versos ejecutan un giro en la conceptualización de esta herencia, pues de nuevo se produce un retorno tropológico al arraigo y la fecundación. La acción inspiradora rosaliana se compara a la de una madre — «mai»— que, en su ejercicio reproductor itinerante, parece asumir la condición tradicionalmente masculina de la actividad fecundadora. La materia fecundada está constituida por un «nós», una pluralidad de seres que, al quedar «semeados de ti», desvela la valencia de un sujeto colectivo concebido inequívocamente como comunidad unida por un idéntico origen germinativo. Y es esta comunidad la que acaba siendo sometida a una lógica estabilizadora y asentada: no en vano se nos dice que 
son «como a terra en lentura». Es más: este esfuerzo aterrizador acaba revirtiendo sobre la propia volatilidad rosaliana, en la medida en que su potencial estimulador acaba confinado a un espacio concebido como «fondo» hecho de «lamas» de las que surgirá la fructificación poética del «verbo»:

\author{
E agora en nós, \\ tan húmedos de mai, semeados de ti \\ como a terra en lentura, o verbo xurde \\ das lamas para sempre do teu fondo.
}

No en vano, en el ensayo citado, Valente definía a Castro como «[f]orma, fundamentación, matriz» (2008: 1340), enlazando con la socorrida idea de Rosalía como metáfora de la nación a través de su poder poético de modelación terrestre. En este sentido, no puede obviarse tampoco la huella de Heidegger (1994), que trataba de asegurar estabilidad ontológica a través de un habitar poético sobre la tierra, algo que testaba sobre los versos de Hölderlin (2005). Como se sabe, los planteamientos poéticos del alemán han sido claves para conformar la veta de modernidad poética en la que se inscribe Valente, como ha estudiado, entre otros, Mayhew (2009), pero además, su influjo resultó fundamental a la hora de conformar el programa identitario de los autores pertenecientes al grupo Galaxia, que se aproximaron a Rosalía desde una perspectiva esencialista que tuvo una plasmación fundamental en el volumen colectivo 7 ensaios sobre Rosalía, publicado en 1952, que Valente leyó con atención ${ }^{16}$. Recientemente, Rábade Villar ha dado nuevos datos sobre la naturaleza de esta influencia, que certifica y refuerza la continuidad, no exenta de matices, entre el discurso cultural de la Galicia interior de mediados del siglo pasado y los pilares erigidos por la Xeración Nós y que tiene que ver con el protagonismo de un núcleo de asentamiento provincial y periférico claramente

16 Como se explica en la nota 12, Valente tenía en su biblioteca los 7 ensaios, con numerosas marcas de lectura. En el capítulo que Vicente Risco redacta para la Historia de Díaz-Plaja, ya aludida, informa de la veta interpretativa «trascendental» que ensayan los miembros del grupo Galaxia y cita, al respecto, estos versos de Follas novas (1880): «Xa nin rencor nin desprezo, / xa nin temor de mudanzas; / tan só unha sede..., unha sede / dun non sei qué que me mata» (Castro, en Risco, 1957: 373). Son los mismos que, junto con otros, apunta Valente en su Diario anónimo el 27 de enero de 1991, apostillando: "(Do Libro primeiro de Follas novas, 1880). Tema de la noche interior. Tema del balbuceo» (2011: 285). 
identificado como rural, frente a las dinámicas negativas del progreso urbano y descentralizador (Rábade Villar, 2019) ${ }^{17}$.

No puede dejar de advertirse en la cántiga tercera (Valente, 2006: 509) un acopio de todos los topoi vistos hasta ahora, que aparecen desplegados en un auténtico diálogo intertextual con Castro en el que se formula un regreso que parece contestar las elegías al éxodo contenidas en múltiples poemas de Follas novas, pero que también encuentran cultivo en los Cantares. En concreto, parece desplegar un escenario de retorno a los cementerios evocados en «Adios, ríos; adios, fontes», en el que la voz lírica rosaliana se despedía de las «herbiñas do camposanto, / onde meu pai se enterrou» íntimamente conectado con esa «terriña que nos criou» (Castro, 2013: 186) ${ }^{18}$. En el texto de Valente, el yo lírico saluda mediante un apóstrofe a una madre — «Escoita, mai, voltei» — para anunciarle su vuelta al lugar donde reposa el cadáver de su abuelo: «Estou no adro / onde aquel día o grande corpo / do meu abó ficou». El poema reza así:

Escoita, mai, voltei.

Estou no adro

onde aquel día o grande corpo

do meu abó ficou.

Inda oio o pranto.

Voltei. Nunca partira.

Alongarme somente foi o xeito

de ficar para sempre.

17 En una conferencia plenaria pronunciada en el III Simposio Norteamericano de Estudos Galegos, celebrado en Denver en octubre de 2018, RábadeVillar alude a la relevancia que el ensayo «Schöpferische Landschaft: Warum bleiben wir in der Provinz ?», que Heidegger escribió en 1933, tendría para los miembros del grupo Galaxia, sobre todo a partir de la traducción que de él realiza Domingo García-Sabell en 1964. Rábade Villar explora el exitoso recorrido que las dicotomías trazadas por el pensador alemán en este texto tendrían en la conceptualización binaria de la cultura gallega a través de categorías como centro-periferia o aldea-ciudad. Agradezco a la autora que me haya brindado la oportunidad de leer su texto, todavía inédito.

18 También en el poema de Follas novas que comienza «Padrón...!, Padrón...! / Santa María... Lestrobe... / Adios! Adios!» alude al «simiterio de Adina» calificándolo de «encantador» (Castro, 2016: 184). 
Tanto en Rosalía como en Valente, la tierra es, efectivamente, matriz de vida, pero, también, lugar donde reposan los muertos. Ahí radica la más definitiva de las permanencias, que quizá no hace más que ratificar una permanencia anterior, esencial, inasequible a cualquier hostigamiento de una movilidad necesariamente accidental. No otra cosa dicen, en el fondo, los célebres versos que cierran la composición: «Voltei. Nunca partira. / Alongarme somente foi o xeito / de ficar para sempre» (Valente, 2006: 509).

\section{LO POPULAR Y LO SINIESTRO. \\ LA DIFÍCIL HERENCIA DE \\ VICENTE RISCO (CON UNA NOTA \\ INÉDITA DE SU HIJO ANTÓN)}

Toda esta dinámica, sin embargo, no agota las huellas rosalianas en Valente. Quizás haya que rastrear un derrotero especialmente productivo de estas en otros lugares textuales y en mediaciones hermenéuticas parcialmente diferentes. Un peso insoslayable del influjo de la tradición gallega tiene que ver, a mi parecer, con una presencia de lo popular concebido como recurso de extrañamiento que halla, también, apoyos en ciertas aristas marginales de la tradición analizada. Encontramos sugestivas pistas en el Diario anónimo. En las entradas del 25 y del 27 de enero de 1991,Valente reproduce varias citas rosalianas pertenecientes a Cantares gallegos y a Follas novas respectivamente. Al lado de la primera de ellas, que transcribe los versos del estribillo popular glosado por Rosalía en su cantar cuarto — «Cantan os galos pra o dia; / érguete, meu ben, e vaite» ${ }^{19}$-, él mismo escribe, para introducirlos, la siguiente anotación: «Dos Cantares Gallegos. No amanece el cantor» (2011: 282). Parece obvio que Valente estaba releyendo a Castro en el periodo en el que redactaba el volumen que vería la luz en 1992, y Carmen Blanco, que ha estudiado los vínculos entre Rosalía y Valente a partir de estas anotaciones, ha identificado certeramente la conexión implícita entre la albada popular que recrea Rosalía y la radical negación de la aurora que Valente escoge como imagen para expresar la imposibilidad del duelo en la elegía compuesta a la muerte de su hijo (2013:25).

19 Los versos están reproducidos según los transcribe Valente en el Diario mencionado. 
Mi intención es, no obstante, partir de esas citas de los Cantares para iluminar otro engarce singular que hermana nuevamente a Valente con Castro a través de la aparición de lo siniestro. Frente al énfasis que la crítica ha hecho en la "paxariña», que subraya el carácter bucólico de la lírica medieval a través de la impronta de las Cantigas alfonsianas en las Cántigas de Valente ${ }^{20}$, otra ave reclama nuestra atención desde las anotaciones del Diario. Se trata de la figura del «moucho» (búho), que aparece justo a continuación de los versos alusivos al alba.Valente escribe:

Eu ben vir estar o moucho enriba daquel penedo.

¡Non che teño medo, moucho; moucho, non che teño medo!

(Moucho que estás no penedo eres de cartón, eres de cartón) $(2011: 283)^{21}$.

Pero, además, en estos versos, Valente efectúa un llamativo collage: los cuatro primeros versos están copiados del cantar 16 de Cantares gallegos, que a su vez los toma del acervo popular. Una variación de ellos había sido elegida, también, por Valle-Inclán para cerrar «Sol de la tarde», una composición de Aromas de leyenda (1907), donde el tratamiento decadentista del espacio galaico quedaba subvertido con la elección de cantares populares al final de las piezas ${ }^{22}$. En una

20 Rodríguez Fer ha estudiado esta intertextualidad en varios trabajos, y apunta a que procede de la "paxariña» presente en la pieza CIII de las Cantigas alfonsíes. Así lo recuerda en Valente infinito (2018: 104-108). Agradezco al autor que me hubiera facilitado esta contribución reciente en la que reúne y revisa algunas de sus esenciales aportaciones al estudio de la vida y de la obra de Valente.

21 A pesar de que en la versión publicada del Diario anónimo, de la que tomamos la cita arriba consignada, aparece transcrita la palabra «moncho», hemos realizado esta enmienda, pues todo parece indicar que se refiere a "moucho», ya que así es como aparece en la obra rosaliana (Castro, 2013: 188). Por una parte, la palabra «moncho» no aparece en ninguna de las tres versiones de los Cantares que Valente custodiaba en su biblioteca; además, "*moncho», en gallego, es un hipocorístico del antropónimo "Ramón» y, por tanto, debería ir en mayúscula. Todo parece apuntar a un error en la transcripción del manuscrito del Diario anónimo, hipótesis que se hace especialmente plausible si tenemos en cuenta la semejanza entre las grafias de la «n» y la «u» en la caligrafía de Valente.

22 La última estrofa de esta pieza dice así: «Sol de la tarde, que ponías el reflejo / de tu lumbre lejana, como un reír de viejo, / en la torre de aquella casa, nido de hidalgos, / con aroma de mosto en el zaguán y galgos / atados en la puerta: La casa que fue mía, / de donde peregrino y pobre, salí un día. / CANDO O 
doble vuelta de tuerca,Valente añade otros dos versos que también proceden de otras coplas populares gallegas, distintas a las recreadas por Rosalía: «(Moucho que estás no penedo / eres de cartón, eres de cartón)». De hecho, estos dos versos están documentados y aparecen consignados en el Cantigueiro popular da Limia Baixa ${ }^{23}$ por Xaquín Lorenzo Fernández (Xocas), amigo de Valente, quien registra asimismo otras variaciones de este tema (Lorenzo Fernández, 1973: 79, 107) ${ }^{24}$, lo que certifica la potente presencia del búho en el folklore gallego. El propio Risco, en el volumen que redactó con Amador Rodríguez Martínez en 1933, Terra de Melide, muestra de los esfuerzos etnográficos de su generación, explica los valores funestos de este animal (Risco y Rodríguez Martínez, 1933: 8), que también recogen antropólogos como Lisón Tolosana, quien lo identifica, junto al cuervo y la lechuza, como "paxaro da morte» (2008: 110). Pero el diálogo intertextual que establecen los versos recogidos por Rosalía con los aportados por Valente exacerba sobre todo el vigoroso componente de parodia y desinhibición subversiva con que se trataba de conjurar lo negativo en esta misma tradición popular, que también aprovechabaValle. Su función desautomatizadora parece innegable.

La figura del búho viene, así, a introducir un componente de burla ante lo que se percibe como una amenaza de desestabilización ontológica. Los cantares populares escogen la chanza como defensa — «non che teño medo»; "eres de cartón»- ante un elemento inquietante que perturba lo conocido. En ese sentido, conforma una perfecta encarnación de lo siniestro y, al situar la alteridad en el seno mismo de la subjetividad, ejecuta una apertura radical que cuestiona el concepto de identidad desde su mismo núcleo. Es una idea no muy distinta de algunas de las formulaciones vistas: basándose en

SOL ESMORECÍA / VIN O MOUCHO NUN PENEDO... / ¡NON CHE TEÑO MEDO MOUCHO, / MOUCHO NON CHE TEÑO MEDO!» (Valle-Inclán, 1991: 74). No resulta difícil suponer que Valente tenía en mente esta composición cuando escribió el cantar rosaliano, conocida la admiración que le profesaba al autor de Luces de bohemia. Explica Rodríguez Fer (2012: 84) que Valle es «el autor nacido en Galicia del que figuran más libros en su biblioteca».

23 La Limia Baixa es una comarca situada el sur de Ourense y yuxtapuesta a la frontera con Portugal.

24 Una de las variantes que anota Lorenzo Fernández (1973: 107) presenta ya la peculiar síntesis que realiza Valente en su Diario. Así, la pieza 1426 reza: «Moucho que estás no penedo, / eres de cartón, non che teño medo». 
Castelao, Valente reconoce en el nacionalismo gallego la postulación de una «identidad interiormente traicionada» (2008: 1343) que acaba potenciando una heterocaracterización fundada en el desconocimiento y la mixtificación. Y desde ella se explica el horizonte de negatividad existencial y ontológica trazado en el poema "Figura» (2006: 523), presidido, precisamente, por la intimidatoria imagen del «moucho» avistado, no casualmente, en la lejanía:

De todo o que non fun

ficou a ausencia,

máis real que nos mesmos.

Coitelo da door do que non fumos, fondo ferir o pranto do non nado.

Outeiros onde vín o moucho lonxe, corredoiras da noite e sombra sombrecida a dos meus eus sen mín fuxidos.

Camiño que non fixen, amor que non amei e nome cego. de mín que ardeu sen terme dado sido.

El íntimo desasosiego que instaura esa mirada acechante no es del todo ajeno a algunas de las inflexiones del alén de Risco contenidas en el texto de 1922. En las palabras finales, este acaba desdiciéndose parcialmente del grueso de su planteamiento para preguntarse: «Alén, alén... E si o alén non estivera alén?» (Risco, 1982: 56), y, seguidamente, esbozar una respuesta en la que relaciona este concepto con una interiorización del espectro ominoso de los antepasados, que vendrían a vigilarnos desde nuestra propia mente: «As almas dos que se foron, cecais andan o redor de nós, dentro de nós mais ben. Non son nada alleo á nosa vida: tecen connosco a trama dos autos no-sos; ollan a nosa vida dend'adentro das noas concencias... Mirade ben o que facedes: estades sempre na presencia sua...» (1982: 56).

Las palabras del autor de O porco de pé enuncian, sin duda, la condición problemática de todo tipo de herencias, tanto materiales como simbólicas. En este sentido, encuentran una inmejorable ejemplificación en el problema de interpretación que ha venido suponiendo la propia figura de Vicente Risco en el ámbito de la cultura gallega. Como es sabido, pasó del galleguismo tradicionalista 
al fascismo, y se convirtió en un aliado de la dictadura franquista, lo que le garantizó una situación cómoda y resguardada en un momento en que las trayectorias de muchos de sus antiguos compañeros de viaje se topaban con la represión y el exilio. En un artículo reciente, Alonso Nogueira (2017) examina las distintas gestiones de lo que denomina la "posición-Risco", y se centra sobre todo en la revisión que de ella realiza Carlos Casares, a la altura de 1996, en su novela alegórica Deus sentado nun sillón azul, que Alonso Nogueira ve como precursora de las narrativas de la memoria que adquirirían hegemonía en el espacio literario estatal desde finales de los 90. Pero, como él explica, la polémica sobre los avatares ideológicos de Risco venía de lejos y había tenido un episodio particularmente señalado en 1963, cuando se publica, meses antes de la muerte de Risco, la monografía Vicente Risco na cultura galega, escrita por Ramón Lugrís y encabezada por un prólogo de Ramón Piñeiro, director de la editorial Galaxia y cabeza visible de la gestión cultural de la Galicia interior posfranquista (Alonso Nogueira, 2017: 128). Los términos de la lectura de Piñeiro ensayaban una interpretación psicológica de la aciaga tercera etapa de Risco para esgrimir una defensa del intelectual: había sido el miedo, lógico ante la extremosidad del peligro al que estaban abocados quienes habían mantenido actividades galleguistas antes de la guerra, lo que explicaría el viraje totalitario e incluso antisemita del autor (Piñeiro, 1963:12). El carácter un tanto capcioso de la argumentación y el momento poco afortunado de su publicación, que acabó coincidiendo prácticamente con la muerte de Risco, provocará la contestación agria de José Luis Varela y Manuel Casado Nieto, quienes acusarán a Piñeiro de "canibalismo moral», en una polémica fácilmente rastreable a través del epistolario que mantuvo, por esas fechas, Piñeiro con Carballo Calero y con Antón Fraguas, entre otros ${ }^{25}$.

A ella no fue ajena Valente, sino que desde su conocimiento quizás se pueda arrojar luz sobre algunas declaraciones y actitudes del autor de las Cántigas que pueden leerse como una toma de posición, tácita y tangencial, sobre el legado simbólico asociado a su paisano. $\mathrm{Y}$, de nuevo, los materiales no estrictamente literarios proporcionan vías de acceso insospechadas. En la biblioteca personal de Valente,

25 Pueden verse numerosos testimonios de este desencuentro en este epistolario. Consúltese, por ejemplo, la larga exposición de motivos que realiza Piñeiro en las cartas enviadas a Isidoro Millán el 26 de noviembre de 1964 y el 26 de octubre del mismo año (Piñeiro, 2009: 144-146, 147-153). 
atesorada como se sabe en la Cátedra José Ángel Valente de Poesía y Estética de la Facultade de Filoloxía de Santiago de Compostela, se conservan los volúmenes de Vicente Risco referidos en la nota 4, y numerosos ejemplares de la obra de su hijo Antón, con quienValente mantuvo una larga relación trasatlántica y básicamente epistolar a lo largo de su vida, desde que ambos fueran compañeros en el instituto de Ourense (Rodríguez Fer, 2012: 68). Las dedicatorias de muchos de estos libros del que fue catedrático de Lengua castellana y portuguesa en Quebec indican que Antón Risco mandaba regularmente sus publicaciones aValente y su familia. Uno de estos volúmenes lleva por título Pensamento de Vicente Risco, y es un ejemplar del breve libro que escribe sobre su padre y que ve la luz en 1978. En su interior se conserva la tarjeta que envía a los Valente, que está inédita ${ }^{26}$, y en la que Antón Risco ofrece un relato interesante no solo sobre las condiciones de escritura y edición del texto sino, sobre todo, sobre la naturaleza de este como una intervención ante lo que identifica como ataques a su padre. Fechada el 11 de diciembre, probablemente de 1978, en Quebec, dice:

\begin{abstract}
Ahí os envío un breve artículo que había hecho sobre mi padre y que, como ninguna revista gallega quería publicarlo (a causa de un ataque a Ramón Piñeiro, y que a mí no me parece tan fuerte, ni mucho menos), un editor de Lugo quiso sacarlo en libro, lo que resultó sin duda muy desproporcionado, pues el texto no tiene densidad para tanto. [...] Pero, en fin, ahí está en espera de que me ponga a hacer algo más extenso y serio. Quizá os sorprendan ciertos excesos ideológicos pero que tenían un carácter provocador destinado a ciertos grupos fanáticos y vociferantes ${ }^{27}$.
\end{abstract}

26 Todo parece indicar que es así. El epistolario de Vicente Risco y Antón Risco a Valente ha sido estudiado por Alba Fernández Méndez en un artículo en el que sintetiza las claves temáticas de este intercambio, pero en el que solo proporciona la reproducción gráfica de dos cartas enviadas por Antón y Vicente (Fernández Méndez, 2015: 132,133), respectivamente, al autor de las Cántigas, así como una de este a los anteriores. En un momento dado, alude a que Antón Risco transmitía en ocasiones a Valente "el rechazo que siente hacia ciertas publicaciones» (2015: 129), pero no da más datos sobre ello. El artículo procede de un Trabajo de Fin de Grado presentado en la Facultade de Humanidades de la Universidade de Santiago de Compostela, que no me ha sido posible consultar.

27 Es necesario transcribir los términos del «ataque» de Antón Risco a Piñeiro para entender, también, esta alusión a "ciertos excesos ideológicos» que pudieran sorprender a Valente, y es que el primero interpreta la trayectoria de su padre como de una absoluta «independencia» tanto ideológica como intelectual que explica 
El documento es interesante por varias razones. Informa sobre un hecho concreto que parece corroborar el carácter casi caudillesco del liderazgo cultural encarnado por Piñeiro durante la dictadura. Valente lo leyó: el ejemplar está lleno de marcas que corrigen las erratas del texto. El conocimiento de este documento quizá pueda permitir postular que las Cántigas de alén efectúan un posicionamiento meridianamente claro, a través de una dedicatoria dirigida a un autor tildado de «mestre» y cuyo legado se reivindica explícitamente, pues está realizada «na memoria», en un periodo en el que esta estaba siendo cuestionada. No hay que olvidar que, aunque el prólogo de Piñeiro databa de 1963, la respuesta de Antón Risco aparecía quince años después, en 1978, y que la novela de Casares se publica en 1996, lo que indica la continuidad en el tiempo del debate. Pero, más allá de la probable intervención de Valente en él, el entramado en el que este breve texto encuentra sentido ofrece también síntomas reveladores del funcionamiento de las alianzas intelectuales y culturales, a menudo traspasadas por el poder trastornador de los afectos, que alteran coherencias y tejen sus propias conexiones más allá de las alineaciones ideológicas y literarias. Es muy interesante la marginalia de la biblioteca del autor: en el ejemplar de la monografía Vicente Risco, que Carlos Casares publica en 1981, Valente dialoga con el autor a propósito de los episodios más insidiosos de la carrera de Risco. Así, cuando se narra la participación de este en el acto público que repuso el Cristo el 30 de agosto de 1936 en la Escuela

su no posicionamiento ante los avatares políticos e históricos que le tocó vivir. Dice Antón Risco en el mencionado ensayo: «Tan personal aventura intelectual, difícilmente comprensible en la España de los años treinta y cuarenta — "aquí solo interesa Lope de Vega", le oí decir a menudo-, le acarreó una marginación de la cual penaba hasta hoy, incluso en Galicia, por no encajar en ninguno de los grupos y capillas que se repartían, y tan dogmáticamente, el control de la cultura del país. Marginación que soportó estoicamente y con ejemplar dignidad, por ser el precio de su independencia, una independencia que mantuvo valientemente, incluso en momentos tan difíciles como los del frente popular y de la guerra civil, momentos en que llegó a quedarse completamente solo entre unos y otros con una honestidad intelectual y un valor que contradice absolutamente el lamentable dictamen de alguien que solo llegó a conocerlo muy de lejos - lo que cuenta aquí, ya que es algo que no pone en cuestión su obra, sino un momento de su biografia-, Ramón Piñeiro. Solo por defender una mediocre posición política personal, Piñeiro publicó aquel lamentable prólogo al libro de Lugrís sobre el ensayo gallego de Risco, y en el más inoportuno momento, pues fue redactado pocos meses después de su fallecimiento. No creo que le haya resultado muy rentable. Por fortuna la actualidad cultural viene en defensa de la obra de Risco» (Martínez Risco, 1978: 65-67). 
de Magisterio de Ourense, de la que era director, y se reproduce el discurso que pronuncia ese mismo día ante el Teniente Coronel de la Guardia Civil en la procesión que siguió al acto (Casares, 1981:103105), Valente escribe con evidente voluntad exculpatoria: «También Otero y Noriega Varela saludan la reposición del Xto. Ver Rodríguez Fer». Cuando desde el diario ourensano La Región, con motivo de la dedicatoria del Día das Letras Galegas a Risco, le proponen escribir sobre él, explica en carta a su amigo Julio Rivera Rodríguez que «[d]e Orense es mejor no hablar. Ahora me piden que escriba algo sobre Risco para La Región. No lo haré. Orense nunca quiso ni supo entender nada de las cosas que él representó. Es una ciudad con una larga y lamentable tradición de opacidad y de sordera» (Valente, en Rodríguez Fer, 2012: 132). Algunos hechos muestran que disculpa a Risco lo que no perdona a Cunqueiro, pues al hablar de su posible pertenencia generacional, propuesta por Méndez Ferrín, a la denominada "promoción de enlace» de la literatura gallega,Valente repasa los rasgos que le unen a un grupo en el que distingue varias posiciones respecto al uso del gallego, para concluir deslizando una mención a "os que escolleron o uso fascista - naquel contexto- do castelán, como foi — dito sexa sen querer facer ningunha crítica, é un feito-Álvaro Cunqueiro» (2008: 1539).

En «Crítica y pensamiento literario gallego en el siglo xx", el extenso capítulo con el que contribuye al volumen colectivo Pensamiento y crítica literaria en el siglo Xx (castellano, catalán, euskera, gallego), Rábade Villar traza lo que denomina «una historia materialista de las ideas literarias en Galicia» (2019: 613), desde la que examina las múltiples tensiones que traspasan el desarrollo de la cultura gallega moderna y contemporánea, un espacio marcado por la multiplicidad, el conflicto y la diáspora. Solo en el seno de esta apertura conceptual, que Rábade Villar había propuesto ya en Fogar impronunciable (2011) y para cuya articulación se apoya con frecuencia en epistolarios y materiales que inciden en la relevancia de lo privado y cuestionan el fetichismo del texto literario cerrado, puede comprenderse la peculiar incardinación de un escritor como José Ángel Valente en ella. Exiliado voluntario en Madrid, Oxford, Ginebra, París y Almería, y autor de una obra bilingüe en la que el uso del castellano domina cuantitativamente, las páginas que anteceden han pretendido demostrar su diálogo animoso no solo con los núcleos nodales de la tradición cultural gallega, sino, también, con las figuras y debates a ella asociados, y han apuntado a 
la existencia de determinados arbitrajes culturales que han operado a modo de censura y que sitúan en las redes del exilio el dinamismo de la libertad.

$\mathrm{Ni}$ el criterio filológico ni el territorial contribuyen a arrojar luz sobre una carrera vital, intelectual y creativa cuya complejidad, en el fondo, no es aislada, sino que inflexiona gran parte de las inopinadas trayectorias de la comunidad intelectual contemporánea. Solo una perspectiva que se sitúe más allá de los rígidos binarismos (castellano/gallego; interior/exterior) que han operado como elementos identitarios un tanto miopes puede iluminarlas. Quizá, después de todo, eso signifique el alén. 


\section{BIBLIOGRAFÍA}

Alonso Nogueira, Alex (2017). «O Deus de Carlos Casares e a ficción no tempo da memoria», Boletín da Real Academia Galega, 378, pp. 117-144.

Blanco, Carmen (2000). «Lugar alén. Unha verea na que escoitar as Cántigas de Valente», Moenia, 6, pp. 25-39.

- (2013). «Valente Rosalía: Cantares gallegos no Diario

anónimo", Cadernos Ramón Piñeiro, 26, pp. 23-31.

Casares, Carlos (1981). Vicente Risco, Vigo, Galaxia.

Castro, Rosalía de (2013). Cantares gallegos, ed. Anxo Angueira,Vigo, Xerais.

— (2016). Follas novas, ed. Anxo Angueira,Vigo, Xerais.

— (2019). En las orillas del Sar, ed. Anxo Angueira,Vigo, Xerais.

Fernández Méndez, Alba (2015). «Vidas entrelazadas: Cartas de Vicente y Antón Risco a José Ángel Valente», Evohé. Revista Cultural do Campus de Lugo, 26, pp. 123-134.

Fernández Rodríguez, Manuel (2008). «José Ángel Valente, el exilio como raíz», en Valente: el fulgor y las tinieblas, ed. Claudio Rodríguez Fer, Lugo, Axac, pp. 139-151.

Ferrari, Marta Beatriz (2017). "A retórica da elexía funeraria no poemario $A$ mi madre de Rosalía de Castro», Boletín Galego de Literatura, 51, pp. 43-54.

García CANDEIra, Margarita (2013). «"Eterno inretorno”: melancolía e desterritorialización nas Cántigas de alén de José Ángel Valente», Abriu, 2, pp. 109-122.

— y Francisco Xavier Redondo Abal (eds.) (2016). Biblioteca de José Ángel Valente, Santiago de Compostela, Publicaciones de la Cátedra José Ángel Valente de Poesía y Estética.

Heidegger, Martin (1994). «... Poéticamente habita el hombre», en Conferencias y artículos, Barcelona, Ediciones del Serbal, pp. 139-151.

— (2005). Aclaraciones a la poesía de Hölderlin, Madrid, Alianza.

Lisón Tolosana, Carmelo (2008). De la estación del amor al diálogo con la muerte (en la Galicia profunda), Madrid, Akal.

Lorenzo Fernández, Xaquín (1973). Cantigueiro popular da Limia Baixa, Ourense, Deputación de Ourense y Museo do Pobo Galego.

Martínez Risco, Antón (1978). Pensamento de Vicente Risco, Lugo, Alvarellos.

Martínez-Falero, Luis (2010). «Las Cántigas de alén de José Ángel Valente: tradición y ruptura de la poesía gallega», Madrygal, 13, pp. 79-87. 
Mayhew, Jonathan (1991). «El signo de la feminidad: Gender and Poetic Creation in José Ángel Valente», Revista de Estudios Hispánicos, 25.2, pp. 123-133.

— (1997). «Valente/Tàpies: The Poetics of Materiality», Anales de la Literatura Española Contemporánea, 22.1/2, pp. 91-102.

— (2009). «José Ángel Valente's Lectura de Paul Celan:Translation and the Heideggerian Tradition in Spain», en The Twilight of the Avant-garde. Spanish Poetry, 1980-2000, Liverpool, Liverpool University Press, pp. 83-102.

Mera Herbello, Heitor (2002). «Análise crítica das Cántigas de alén de José Ángel Valente», Revista de Lengua y Literatura Catalana, Gallega y Vasca, 8, pp. 139-156.

Miguélez-Carballeira, Helena (2014). Galiza, un povo sentimental? Género, política e cultura no imaginário nacional galego, Santiago de Compostela, Através Editora / AGAL.

Pimentel, Luis et al. (1952). 7 ensayos sobre Rosalía,Vigo, Galaxia.

PiÑEIro, Ramón (1963). «Prólogo», en Ramón Lugrís, Vicente Risco na cultura galega, Vigo, Galaxia, pp. 7-15.

— (2009). Epistolario de Ramón Piñeiro a Isidoro Millán González-Pardo (1952-1990), Santiago de Compostela, Centro Ramón Piñeiro para a Investigación en Humanidades. Rábade Villar, María do Cebreiro (2009). «Los límites del poema no son los límites del mundo: una lectura de Cántigas de alén», La Página, 78-79, pp. 129-139.

- (2011). Fogar impronunciable. Poesía e pantasma,Vigo, Galaxia.

- (2018a). «Cuerpos desenterrados: Rosalía de Castro como santa cultural», CELEHIS. Revista del Centro de Letras Hispanoamericanas, 27.36, pp. 16-28.

— (2018b). «Un lugar onde nacer e un lugar onde morrer. Desprazamento e radicación na cultura galega contemporánea», Conferencia pronunciada en el III Simposio Norteamericano de Estudos Galegos. Estudos Galegos rumbo ao oeste: lingua e cultura galegas na encrucillada, celebrado en Denver entre el 18 y el 20 de octubre de 2018. Inédita.

- (2019). «Crítica y pensamiento literario gallego en el siglo xx», en José María Pozuelo Yvancos, Mariángeles Rodríguez Alonso, Pere Ballart, Jordi Julià, Mari Jose Olaziregi, Lourdes Otaegui y María do Cebreiro Rábade Villar, Pensamiento y crítica literaria en el siglo Xx (castellano, catalán, euskera, gallego), Madrid, Cátedra, pp. 607-770.

Risco,Vicente (1920). Teoría do nacionalismo galego, Ourense, La Región. Edición facsímil.

- (1957). "La poesía gallega en el siglo XIX», en Historia general de las literaturas hispánicas. Tomo IV, ed. Guillermo Díaz-Plaja, Barcelona, Barna, pp. 369-381.

— (1961). Leria,Vigo, Galaxia.

- (1970). Leria,Vigo, Galaxia. 
— (1982). Prosas de Risco en La Zarpa (1921-1923), Orense, La Región.

— (1990). Leria, Vigo, Galaxia.

- y Amador Rodríguez Martínez (1933). Terra de

Melide, Santiago de Compostela, Nós.

Rodríguez Fer, Claudio (1992). «La poesía gallega de José Ángel Valente», en José Ángel Valente. El escritor y la crítica, ed. Claudio Rodríguez Fer, Madrid, Taurus, pp. 79-111.

_ (1995). «Valente en la lengua del origen», en El silencio y la escucha. José Ángel Valente, ed. Teresa Hernández Fernández, Madrid, Cátedra y Ministerio de Cultura, pp. 119-141.

— (2012). «Valente en Galicia: Quedar para sempre», en Valente vital

(Galicia, Madrid, Oxford), eds. Claudio Rodríguez Fer, Marta Agudo y

Manuel Fernández Rodríguez, Santiago de Compostela, Publicaciones

de la Cátedra José Ángel Valente de Poesía y Estética, pp. 13-168.

- (2018). Valente infinito (libertad creativa y conexiones interculturales), Santiago de

Compostela, Publicaciones de la Cátedra José Ángel Valente de Poesía y Estética.

Valente, José Ángel (2006). Obras completas I. Poesía y prosa, ed. Andrés

Sánchez Robayna, Barcelona, Galaxia Gutenberg / Círculo de Lectores.

— (2008). Obras completas II. Ensayos, ed. Andrés Sánchez

Robayna, recopilación e introducción de Claudio Rodríguez Fer,

Barcelona, Galaxia Gutenberg / Círculo de Lectores.

— (2011). Diario anónimo (1959-2000), ed. Andrés Sánchez-

Robayna, Barcelona, Galaxia Gutenberg / Círculo de Lectores.

— (2018). El ángel de la creación. Diálogos y entrevistas, ed. Andrés

Sánchez-Robayna, Barcelona, Galaxia Gutenberg.

Valle-InClán, Ramón del (1991). Claves líricas, ed. José-

Carlos Mainer, Barcelona, Círculo de Lectores.

Vallejo, César (2005). Poesía completa, ed. Antonio Merino, Madrid, Akal. 